\title{
Fibroblasts in atherosclerosis
}

Citation for published version (APA):

Tillie, R. J. H. A., van Kuijk, K., \& Sluimer, J. C. (2020). Fibroblasts in atherosclerosis: heterogeneous and plastic participants. Current Opinion in Lipidology, 31(5), 273-278.

https://doi.org/10.1097/MOL.0000000000000700

Document status and date:

Published: 01/10/2020

DOI:

10.1097/MOL.0000000000000700

Document Version:

Publisher's PDF, also known as Version of record

Document license:

Taverne

Please check the document version of this publication:

- A submitted manuscript is the version of the article upon submission and before peer-review. There can be important differences between the submitted version and the official published version of record.

People interested in the research are advised to contact the author for the final version of the publication, or visit the DOI to the publisher's website.

- The final author version and the galley proof are versions of the publication after peer review.

- The final published version features the final layout of the paper including the volume, issue and page numbers.

Link to publication

\footnotetext{
General rights rights.

- You may freely distribute the URL identifying the publication in the public portal. please follow below link for the End User Agreement:

www.umlib.nl/taverne-license

Take down policy

If you believe that this document breaches copyright please contact us at:

repository@maastrichtuniversity.nl

providing details and we will investigate your claim.
}

Copyright and moral rights for the publications made accessible in the public portal are retained by the authors and/or other copyright owners and it is a condition of accessing publications that users recognise and abide by the legal requirements associated with these

- Users may download and print one copy of any publication from the public portal for the purpose of private study or research.

- You may not further distribute the material or use it for any profit-making activity or commercial gain

If the publication is distributed under the terms of Article $25 \mathrm{fa}$ of the Dutch Copyright Act, indicated by the "Taverne" license above, 


\title{
Fibroblasts in atherosclerosis: heterogeneous and plastic participants
}

\author{
Renée J.H.A. Tillie ${ }^{\mathrm{a}}$, Kim van Kuijk ${ }^{\mathrm{a}}$, and Judith C. Sluimer ${ }^{\mathrm{a}, \mathrm{b}}$
}

\begin{abstract}
Purpose of review
Fibroblasts are very heterogeneous and plastic cells in the vasculature. A growing interest in fibroblasts in healthy and atherosclerotic vasculature is observed, next to macrophages, endothelial cells, and smooth muscle cells (SMCs). In this review, we discuss fibroblast presence, heterogeneity, origin, and plasticity in health and atherosclerosis based on latest literature.
\end{abstract}

\section{Recent findings}

With help of single cell sequencing (SCS) techniques, we have gained more insight into presence and functions of fibroblasts in atherosclerosis. Next to SMCs, fibroblasts are extracellular matrix-producing cells abundant in the vasculature and involved in atherogenesis. Fibroblasts encompass a heterogeneous population and SCS data reveal several fibroblast clusters in healthy and atherosclerotic tissue with varying gene expression and function. Moreover, recent findings indicate interesting similarities between adventitial stem and/or progenitor cells and fibroblasts. Also, communication with inflammatory cells opens up a new therapeutic avenue.

\section{Summary}

Because of their highly plastic and heterogeneous nature, modulating fibroblast cell function and communication in the atherosclerotic vessel might be useful in battling atherosclerosis from within the plaque.

\section{Keywords}

atherosclerosis, fibroblast, mesenchymal cell

\section{INTRODUCTION}

Atherosclerosis and its clinical manifestations, for example myocardial infarction and stroke, are currently still the leading causes of death worldwide [1]. Atherosclerosis is characterized by lipid accumulation in the subendothelial space, intimal inflammation, smooth muscle cells (SMC) migration from the media to the outside of the newly formed plaque and ultimately plaque rupture [2]. Different cell types, including endothelial cells, macrophages, and SMCs, play prominent roles in this life-long process [3-5]. However, recent evidence suggests that an additional cell type, the fibroblast, is an important player in matrix production in atherosclerosis. Traditionally, fibroblasts are thought to arise from mesenchymal stem cells (MSCs) and are thus part of the mesenchymal cell category, also including pericytes and SMCs. In arterial injury, adventitial fibroblasts differentiate into activated fibroblasts (myofibroblasts) with de-novo alphasmooth muscle actin ( $\alpha$-SMA) expression in response to proinflammatory cytokines, matrix remodeling, and transforming growth factor beta (TGF- $\beta$ ) signaling. Myofibroblasts have been implicated in extracellular matrix (ECM) production, proinflammatory cytokine, and matrix metalloproteinase (MMP) secretion and leukocyte recruitment [6-8]. However, these traditional views are being overturned by new insights and the advent of single cell sequencing (SCS), which will be discussed in this review.

In fact, the ability to acquire stem cell properties by upregulating markers such as stem cell antigen-1 (Sca-1) enables fibroblasts to be plastic and

\footnotetext{
${ }^{\text {a}}$ Cardiovascular Research Institute Maastricht (CARIM), Department of Pathology, Maastricht University Medical Center, Maastricht, The Netherlands and ${ }^{b} \mathrm{BHF}$ Centre for Cardiovascular Sciences (CVS), University of Edinburgh, Edinburgh, UK

Correspondence to: Judith Sluimer, MUMC, Pathology Department, P. Debyelaan 25 6229HX Maastricht, The Netherlands.

Tel: +31(0)433877675; e-mail: judith.sluimer@maastrichtuniversity.nl
}

Curr Opin Lipidol 2020, 31:273-278

DOI:10.1097/MOL.0000000000000700 


\section{KEY POINTS}

- Fibroblasts are ECM-producing cells abundant in the vasculature and involved in atherogenesis.

- Fibroblasts encompass a very heterogeneous population as indicated by SCS data revealing several fibroblast clusters in healthy and atherosclerotic tissue with varying gene expression and function.

- Fibroblast identity has been proposed for adventitial progenitor and/or stem cells and should be further investigated.

adaptable in numerous environmental situations $\left[9^{-}, 10\right]$. Because of this heterogeneity and plasticity, currently used markers seem insufficient in unique identification of fibroblasts and/or covering the whole fibroblast population. Here, SCS will aid to find markers unique to fibroblasts. Indeed, SCS of healthy mouse brain confirmed the traditional marker platelet-derived growth factor alpha (Pdgfra) and yielded three new markers, decorin, lumican, and Mmp2 [11]. However, both lumican and decorin have been associated with other cell types involved in the advent of atherosclerosis [12"',13]. This may suggest disease and/or organ specificity of markers to identify fibroblasts. The lack of a onesize-fits-all marker makes investigating their role in atherosclerosis development challenging. In this review, we aim to elucidate the functional role of fibroblasts in healthy and atherosclerotic vasculature by discussing fibroblast presence, heterogeneity, origin, and plasticity.

\section{FIBROBLASTS IN HEALTHY VASCULATURE}

The arterial wall consists of three layers. The inner intima is composed of an endothelial cell monolayer. The middle medial layer consists of SMCs embedded in ECM. Finally, the adventitia is the outer layer and is traditionally thought to harbor mesenchymal cells, that is fibroblasts, pericytes and SMCs, connective tissue, unmyelinated nerve fibers, resident leukocytes, small blood vessels with endothelial cells surrounded by mesenchymal cells, and several progenitor cells [8]. Multiple studies have shown the fibroblast's potential to extensively participate in organ homeostasis and repair mechanisms in response to stress [14-16]. The emergence of SCS has provided researchers the opportunity to study vascular cells in more depth. This technique has improved fibroblast annotation and revealed different subsets in multiple organs. Kalluri et al. [17"'] used abovementioned technique to investigate all three layers of the healthy murine aorta. The authors showed that SMCs comprise the largest cell population in the murine aorta ( 40\%), but surprisingly, also showed that fibroblasts make up for roughly $33 \%$ of aortic cells [17"']. These fibroblasts consist of two subpopulations, with a phenotypic gradient rather than a rigid split between them. These fibroblasts are probably derived from the adventitia, although the authors removed perivascular fat - possibly including the adventitia. As their arterial wall location was not validated by immunohistochemistry or in-situ hybridization, a possible medial location for one or both subpopulations is yet to be confirmed. Furthermore, their function, embryonic origin, cellular progeny and fate are yet unknown. Gu et al. studied the adventitia of healthy murine aorta and shed more light on their function. They uncovered four mesenchymal populations, whose differential gene expression suggests functions in ECM organization, immune regulation and bone formation [18"']. These data suggest fibroblast heterogeneity, already present in a healthy steady state.

\section{FIBROBLASTS IN ATHEROSCLEROSIS}

The classical dogma in atherogenesis entails migration of medial SMCs to the newly formed plaque, producing ECM components for fibrous cap formation [2]. This dogma has recently been challenged, as several groups have reported the presence of fibroblast-like cells in human atherosclerotic lesions $[12 " ', 19]$. Also, adventitial fibroblast-like cells have been functionally implicated in plaque ECM production $[19,20]$. Using $\mathrm{ApoE}^{-1-}$ mice on a Western diet superimposed with chronic kidney disease, Kramann et al. [20] showed that a subset of adventitial MSC-like cells, expressing GLI family zinc finger 1 (Gli1), Sca1, and PDGFR $\beta$, migrated into the media and neointima. Gli1+ cells contributed to calcification by differentiation into osteoblast-like cells. In contrast, Evrard et al. [19] reported decreased collagen and increased MMP expression in another subset of endothelial-derived, fibroblast-like cells expressing fibroblast activation protein (Fap) or fibroblast-specific protein 1 (Fsp1, S100a4 gene) in atherosclerosis, indicating a role in matrix degradation. In 2019, a key paper by Wirka et al. [12"'] employed SCS to assess cellular composition in atherosclerotic plaques from human coronary artery and mouse aorta, and identified two fibroblast clusters. Interestingly, Gli1, Fap, or Fsp1 were not among the top 100 differential genes in the two murine or human fibroblast subsets defined by Wirka, complicating the interpretation of the above reference studies and strongly suggesting 
heterogeneity. Together, these studies suggest that fibroblast clusters identified in healthy and diseased tissue differ in functionality, possibly because of different origin and/or differentiation fate.

\section{FIBROBLAST PLASTICITY, HETEROGENEITY, AND ORIGIN IN ATHEROSCLEROSIS}

As described above, varying numbers of fibroblast clusters with corresponding differential gene sets have been identified in healthy and atherosclerotic tissue. Additionally, studies in other organs have shown that new fibroblast clusters can arise as a consequence of disease, further supporting plasticity and heterogeneity [15]. Heterogeneity makes it very difficult to identify the entire fibroblast population and a resulting lack of specific markers complicates fibroblast research. Common fibroblast markers, such as FAP, FSP1, and lumican are not specifically expressed by fibroblast-like cells only, and/or are not expressed by all fibroblasts [21-25]. Fibroblast heterogeneity may be a result of their various origins and enormous plasticity, all enhanced as a result of adaptation to disease. Here, we describe evidence to support that fibroblasts in atherosclerosis may also originate from SMCs and/ or endothelial cells (Fig. 1). Also, we discuss adventitial stem and/or progenitor cells as a source of fibroblasts or possibly a subset of fibroblasts.

\section{Smooth muscle cells origin}

Wirka et al. studied SMC differentiation and their contribution to atherosclerosis in vivo combining SCS and a fluorescent myosin heavy chain 11 (Myh11) reporter strain for SMCs on an $\mathrm{ApoE}^{-/-}$background. In contrast to prevailing concepts of myofibroblast development from fibroblasts, they reported SMC differentiation into fibroblast-like, 'fibromyocyte' cells upon high-fat diet (HFD) [12"-'. In addition to two fibroblast and two SMC clusters in $\mathrm{ApoE}^{-/-}$mice on chow, a Myh11+ SMC cluster appeared and expanded with HFD feeding. This modulated SMC cluster showed decreased expression of SMC differentiation markers, and a clear transcriptional shift towards genes expressed by the fibroblast clusters, later confirmed in human coronary arteries [12"']. Nevertheless, the cells were transcriptionally distinct from fibroblasts and displayed the Myh11-reporter. These data highlighted the benefits of fluorescent fate tracking and lead one to wonder whether these fibroblastlike cells have reached the end stage of their dedifferentiation or will dedifferentiate further into actual fibroblasts. Another question is, does the differentiation also occur the other way around? Comparison between the modulated SMC cluster and a myofibroblast population could be interesting to avoid off-target effects in future cell-specific targeting.

\section{Endothelial origin}

Another possible fibroblast source are endothelial cells, which can undergo endothelial-to-mesenchymal transitioning (EndMT). A review by Kovacic et al. [26"] emphasized the functional importance of EndMT in both healthy and diseased vasculature. EndMT results in downregulation of endothelialassociated genes, such as cluster of differentiation 31 (CD31) or VE-cadherin, and upregulation of mesenchymal genes, such as $\alpha$-SMA and FAP. These cells genetically present as mesenchymal cells and can execute mesenchymal functions like ECM production [26"]. Evrard et al. [19] specifically showed that fibroblasts can arise through EndMT in atherosclerosis. Using a tamoxifen-inducible endothelial lineagetracking system in $\mathrm{ApoE}^{-/-}$mice, they observed onethird of plaque cells positive for Fap were endothelialderived after 8 weeks of HFD. The population expanded to nearly 50\% in advanced atherosclerotic plaques [19]. They showed that EndMT is stimulated in vitro by severe hypoxia, TGF- $\beta$ signaling, and oxidative stress, factors that are ubiquitous in atherosclerosis [19]. Oscillatory shear stress has also been identified as EndMT inducer in atherosclerosis [27]. Importantly, Evrard et al. [19] uncovered a relationship between the extent of EndMT and an unstable plaque phenotype in humans. Notably, the data should be interpreted with slight caution, as the markers used to identify fibroblasts are not unique $[23,24]$. Current SCS publications have not explicitly reported on EndMT, either because it was unstudied or possibly because of lack of sufficient cells to model transitions. However, the reported two fibroblast human subsets could include EndMT-derived cells. The top 100 differential genes do not include endothelial markers, yet this does not exclude low marker expression [12"']. Hence, SCS using endothelial cell reporter strains are yet to fully confirm these findings. In addition, the functional differences between both EndMT-derived and SMC-derived fibroblast (-like) cells and their exact contribution to atherosclerosis remain to be elucidated.

\section{Adventitial stem and/or progenitor cells}

Fibroblasts have been suggested to originate from a pool of adventitial stem and/or progenitor cells. However, the identity of these cells is a point of discussion, as fibroblasts also have the ability to re-acquire stem cell properties by upregulating markers such as Sca-1 $\left[9^{*}, 10,20,28\right]$. Additionally, MSCs and fibroblasts are 


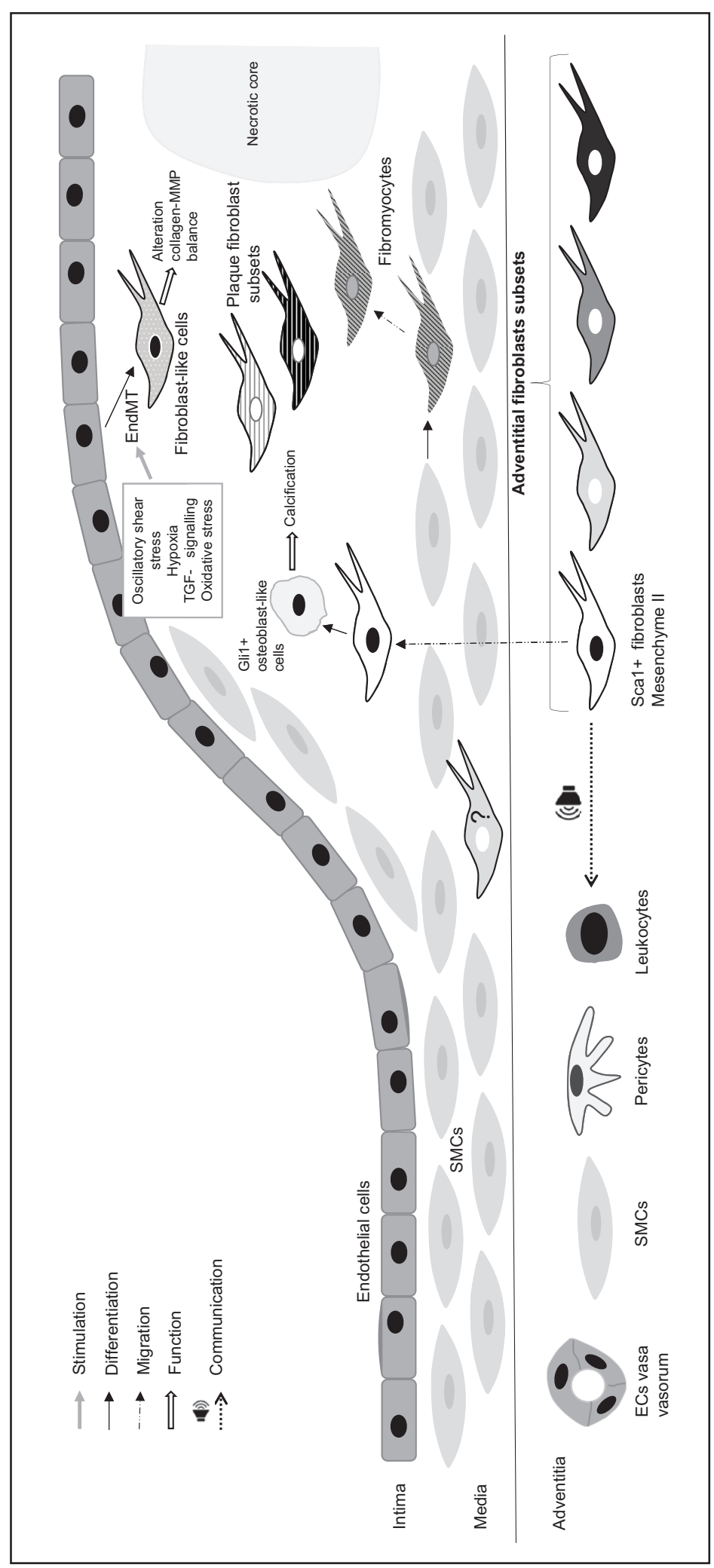

$\overline{\overline{\mathrm{o}}}$

$\frac{0}{0}$

음

要

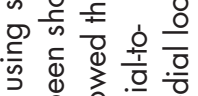

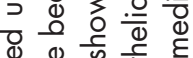

这

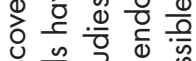

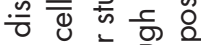

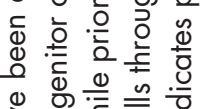

它

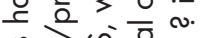

造论

至

究

응 贾产

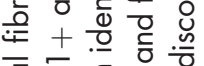

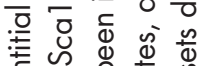

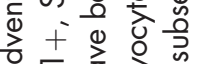

은 方

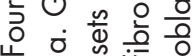

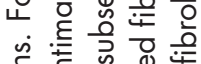

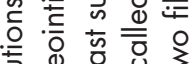

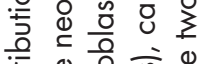

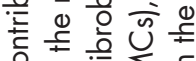

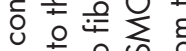

을 은 $\frac{\omega}{5}$

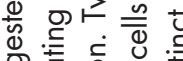

엉 흔 은

可 흠

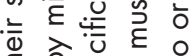

合就 등

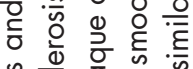

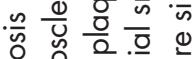

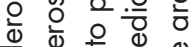

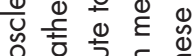

잉오 흥 등

등 논

.

贸产

응 仓

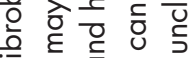

先

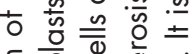

등응 U

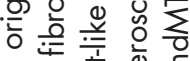

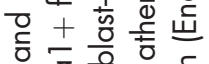

४

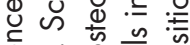

ه্

¿

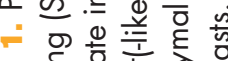

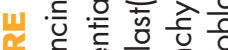

ब

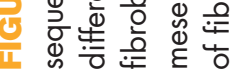


morphologically similar and expression of MSC surface markers, such as CD105, CD73, and CD90, has been observed on fibroblasts. Vice versa, MSC expression of common fibroblast markers, that is vimentin and fibroblast surface protein (FSP) has been reported [9"]. Similar to MSCs, fibroblasts seem capable of differentiation into adipogenic, osteoblastogenic, and chondrogenic lineages [9"]. These insights might suggest that adventitial MSCs and Sca-1+ progenitor cells, previously identified and studied by many groups, are in fact fibroblasts. Indeed, a recent paper by $\mathrm{Ni}$ et al. shows that $10 \%$ of c-Kit + cells was positive for the fibroblast marker PDGFRA in healthy C57Bl6 aorta [29"]. Their findings were confirmed using an inducible Cre model, labeling c-Kit + cells with TdTomato, showing $~ 20 \%$ overlap between PDGFRA and c-Kit [29"]. Moreover, Tang et al. [21,30"] also reported that $40 \%$ of adventitial Sca-1+ cells with progenitor properties coexpressed PDGFRA. These Sca-1+/PDGFRA+, progenitor-like cells generated new medial SMCs after severe artery injury [30"]. Similar to other recent studies that assessed vasculature cell populations by SCS, Gu et al. [18"'] did not annotate mesenchymal clusters in adventitia of $\mathrm{ApoE}^{-/-}$and wildtype aortas as stem or progenitor cells. Yet, one of the four identified mesenchyme clusters showed high Sca-1+ expression, indicating stem cell properties of this cluster [18"']. The distinction between true adventitial stem and/or progenitor cells and fibroblasts may thus be smaller than previously assumed, and expression of Sca1+ indicative of fibroblast plasticity.

Together, these data suggest that fibroblasts show an even greater plasticity than previously thought. Cell transitioning of fibroblasts into other cell types and vice versa seems common and extensive in atherosclerosis. Whether all currently identified adventitial stem and/or progenitor cells are really adventitial fibroblasts and vice versa is an important remaining question to be resolved using reliable fibroblast reporter models. Based on this concept, another question is whether the fibroblast is an end-stage cell or merely a collection of heterogeneous 'in between' cells, actively transitioning between different cell types, or a combination of the two. It would be interesting to study if the acquisition of stem cell-like properties by fibroblasts occurs through dedifferentiation. Assessing the differentiation capacity of the distinct fibroblast clusters into other cell types could also shine some light on this discussion.

\section{FIBROBLAST CELL-CELL COMMUNICATION AND ITS THERAPEUTIC POTENTIAL}

In addition to heterogeneity and function of fibroblasts in the natural development of atherosclerosis, these cells could possibly be used as a new therapeutic approach based on their effect on surrounding inflammatory cells. A proinflammatory role of mesenchyme clusters through increased intercellular communication with inflammatory macrophages has been computationally predicted in $\mathrm{ApoE}^{-1-}$ adventitia by Gu et al. [18"']. A recent paper by Gorabi et al. [31"] also reviewed the possibility of using MSCs as treatment for atherosclerosis by modulating inflammation. Multiple studies discussed in this review showed a marked anti-inflammatory effect in murine atherosclerosis by decreased proinflammatory cytokines and nuclear factor-kappa B signaling after bone marrow MSC administration. MSC therapy has been studied in clinical trials for diseases such as heart disease, cancer and peripheral artery disease, but not atherosclerosis. It is considered a promising future treatment option, but at the same time its safety and efficacy are questioned. Knowledge regarding precise in-vivo mechanisms of action is still lacking and inconsistent results are observed because of cellular heterogeneity of MSCs and a lack of specific markers [32]. Donor characteristics, culture conditions, method and location of delivery, and host receptibility are all factors that can influence MSC therapy efficacy and efficiency [31",32,33]. Moreover, risks of malignant transformation and protumorigenic effects of MSCs have been reported. Thus, extensive additional research into improving efficiency and efficacy of MSC therapy is required before considering this a new therapy option.

\section{CONCLUSION AND FUTURE RESEARCH}

The present review shows that in contrast to the assumptions the classical dogmas contain, next to SMCs, fibroblasts are ECM-producing cells abundant in the vasculature and involved in atherosclerosis. Fibroblasts comprise a very heterogeneous population because of different cellular origins and an extensive repertoire of possible cell transitions. The origin and fate of fibroblasts in atherosclerotic plaques remains to be elucidated. Because of their heterogeneity, there is a lack of specific markers that encompass the entire population making it difficult to study fibroblast (sub)populations in atherosclerosis. Recent comparisons between fibroblasts and adventitial stem and/or progenitor cells indicate similarities between these cells. Moreover, recent SCS data did not identify any adventitial stem and/or progenitor cell clusters, supporting fibroblast identity of these cells. SCS data did identify multiple fibroblast clusters with differential gene expression and functionality per cluster in healthy and atherosclerotic tissue. Further research into subpopulations of fibroblasts and their different functions is needed to identify specific 
markers per subpopulation and to determine the contribution of each subpopulation to atherosclerosis. The emergence of SCS provides opportunities to find answers to the remaining questions in an unbiased way. In the future, modulating fibroblast cell communication in atherosclerotic vessels could be useful in battling atherosclerosis from within the plaque.

\section{Acknowledgements}

None.

\section{Financial support and sponsorship}

Financial support was received from the Netherlands Scientific Organization (NWO VIDI 91718364 to J.C.S.), the Dutch Heart Foundation (Dr Dekker fellowship 2016 T060 to J.C.S.) and the Leducq Foundation Network (A15CVD04 to J.C.S.).

\section{Conflicts of interest}

There are no conflicts of interest.

\section{REFERENCES AND RECOMMENDED}

\section{READING}

Papers of particular interest, published within the annual period of review, have been highlighted as:

- of special interest

m. of outstanding interest

1. Herrington $W$, Lacey $B$, Sherliker $P$, et al. Epidemiology of atherosclerosis and the potential to reduce the global burden of atherothrombotic disease. Circ Res 2016; 118:535-546.

2. Libby P, Buring JE, Badimon L, et al. Atherosclerosis. Nat Rev Dis Prim 2019; $5: 56$.

3. Basatemur $\mathrm{GL}$, Jorgensen $\mathrm{HF}$, Clarke $\mathrm{MCH}$, et al. Vascular smooth muscle cells in atherosclerosis. Nat Rev Cardiol 2019; 16:727-744.

4. Li M, Qian M, Kyler K, Xu J. Endothelial-vascular smooth muscle cells interactions in atherosclerosis. Front Cardiovasc Med 2018; 5:151.

5. Moore KJ, Koplev S, Fisher EA, et al. Macrophage trafficking, inflammatory resolution, and genomics in atherosclerosis: JACC macrophage in CVD series (Part 2). J Am Coll Cardiol 2018; 72:2181-2197.

6. Shi Y, O'Brien JE Jr, Fard A, Zalewski A. Transforming growth factor-beta 1 expression and myofibroblast formation during arterial repair. Arterioscler Thromb Vasc Biol 1996; 16:1298-1305.

7. Sartore $\mathrm{S}$, Chiavegato $\mathrm{A}$, Faggin $\mathrm{E}$, et al. Contribution of adventitial fibroblasts to neointima formation and vascular remodeling: from innocent bystander to active participant. Circ Res 2001; 89:1111-1121.

8. Singh S, Torzewski M. Fibroblasts and their pathological functions in the fibrosis of aortic valve sclerosis and atherosclerosis. Biomolecules 2019; 9:472.

9. Soundararajan M, Kannan S. Fibroblasts and mesenchymal stem cells: two

- sides of the same coin? J Cell Physiol 2018; 233:9099-9109.

This review extensively shows the similarities between fibroblasts and mesenchymal stem cells, supporting the hypothesis that these could be the same cells

10. Ichim TE, O'Heeron $P$, Kesari S. Fibroblasts as a practical alternative to mesenchymal stem cells. J Transl Med 2018; 16:212.

11. Vanlandewijck $M, H e L, M a e ~ M A$, et al. A molecular atlas of cell types and zonation in the brain vasculature. Nature 2018; 554:475-480.

12. Wirka RC, Wagh $D$, Paik DT, et al. Atheroprotective roles of smooth muscle

- cell phenotypic modulation and the TCF21 disease gene as revealed by single-cell analysis. Nat Med 2019; 25:1280-1289.

This papers elegantly combines SCS and a Myh11 reporter strain to study SMC differentiation in and their contribution to atherosclerosis in $\mathrm{ApoE}^{-1-}$ mice. The study identifies two fibroblast clusters in human and murine atherosclerotic plaques. Importantly, the paper reports SMC differentiation into distinct fibroblast-like, 'fibromyocyte' cells upon high-fat diet feeding. This paper is of importance as it indicates SMC origin and highlights the importance and participation of fibroblast(-like) cells in atherosclerosis
13. Do N-N, Willenborg $S$, Eckes $B$, et al. Myeloid cell-restricted STAT3 signaling controls a cell-autonomous antifibrotic repair program. J Immunol 2018; 201:663-674.

14. Guerrero-Juarez CF, Dedhia PH, Jin S, et al. Single-cell analysis reveals fibroblast heterogeneity and myeloid-derived adipocyte progenitors in murine skin wounds. Nat Commun 2019; 10:650.

15. Xie T, Wang $Y$, Deng $N$, et al. Single-cell deconvolution of fibroblast heterogeneity in mouse pulmonary fibrosis. Cell Rep 2018; 22:3625-3640.

16. Gladka MM, Molenaar $B$, de Ruiter $H$, et al. Single-cell sequencing of the healthy and diseased heart reveals cytoskeleton-associated protein 4 as a new modulator of fibroblasts activation. Circulation 2018; 138: $166-180$.

17. Kalluri AS, Vellarikkal SK, Edelman ER, et al. Single-cell analysis of the normal

- mouse aorta reveals functionally distinct endothelial cell populations. Circulation 2019; 140:147-163.

This paper is of importance as it uses SCS to identify and characterize cellular populations in the healthy vasculature. In contrast to prevailing concepts, it shows that next to SMCs, fibroblasts make up a large part of the healthy murine aorta. Furthermore, the paper identifies two fibroblast subpopulations

18. Gu W, Ni Z, Tan YQ, et al. Adventitial cell atlas of wt (Wild Type) and ApoE

- (Apolipoprotein E)-deficient mice defined by single-cell RNA sequencing. Arterioscler Thromb Vasc Biol 2019; 39:1055-1071.

This paper uncovers four mesenchymal cell populations in the adventitia of wild-type and $\mathrm{ApoE}^{-1-}$ mice on chow. It provides insight into possible functions of these fibroblast subpopulations. Furthermore, using computational modeling, the paper suggests increased intercellular communication of mesenchyme clusters with inflammatory macrophages in $\mathrm{ApoE}^{-1-}$ adventitia. This cell-cell communication poses interesting opportunities for future research and treatment

19. Evrard SM, Lecce L, Michelis KC, et al. Endothelial to mesenchymal transition is common in atherosclerotic lesions and is associated with plaque instability. Nat Commun 2016; 7:11853.

20. Kramann R, Goettsch C, Wongboonsin J, et al. Adventitial MSC-like cells are progenitors of vascular smooth muscle cells and drive vascular calcification in chronic kidney disease. Cell Stem Cell 2016; 19:628-642.

21. Kuwabara JT, Tallquist MD. Tracking adventitial fibroblast contribution to disease: a review of current methods to identify resident fibroblasts. Arterioscler Thromb Vasc Biol 2017; 37:1598-1607.

22. Dobnikar L, Taylor AL, Chappell J, et al. Disease-relevant transcriptional signatures identified in individual smooth muscle cells from healthy mouse vessels. Nat Commun 2018; 9:4567.

23. Osterreicher $\mathrm{CH}$, Penz-Osterreicher $\mathrm{M}$, Grivennikov $\mathrm{SI}$, et al. Fibroblastspecific protein 1 identifies an inflammatory subpopulation of macrophages in the liver. Proc Natl Acad Sci U S A 2011; 108:308-313.

24. Kahounova Z, Kurfurstova D, Bouchal J, et al. The fibroblast surface markers FAP, antifibroblast, and FSP are expressed by cells of epithelial origin and may be altered during epithelial-to-mesenchymal transition. Cytometry A 2018; 93:941-951.

25. Lu YP, Ishiwata $T$, Kawahara $K$, et al. Expression of lumican in human colorectal cancer cells. Pathol Int 2002; 52:519-526.

26. Kovacic JC, Dimmeler S, Harvey RP, et al. Endothelial to mesenchymal

- transition in cardiovascular disease: JACC state-of-the-art review. J Am Coll Cardiol 2019; 73:190-209.

Extensive review that describes the occurrence of endothelial to mesenchymal transition in cardiovascular disease and elaborates on possible inducers of EndMT.

27. Lai $\mathrm{B}, \mathrm{Li} \mathrm{Z}, \mathrm{He} \mathrm{M}$, et al. Atheroprone flow enhances the endothelial-tomesenchymal transition. Am J Physiol Heart Circ Physiol 2018; 315: $\mathrm{H} 1293-\mathrm{H} 1303$.

28. Yu B, Chen $\mathrm{Q}$, Le Bras $A$, et al. Vascular stem/progenitor cell migration and differentiation in atherosclerosis. Antioxid Redox Signal 2018; 29:219-235.

29. Ni Z, Deng J, Potter CMF, et al. Recipient c-Kit lineage cells repopulate

smooth muscle cells of transplant Arteriosclerosis in mouse models. Circ Res $2019 ; 125: 223-241$.

This paper reports double positivity for cKit and fibroblast marker PDGFRA of cells in the healthy $\mathrm{C} 57 \mathrm{Bl} 6$ aorta.

30. Tang J, Wang H, Huang $X$, et al. Arterial Sca1 + vascular stem cells generate

- de novo smooth muscle for artery repair and regeneration. Cell Stem Cell 2020; 26:81-96.e4.

This paper reports coexpression of fibroblast marker PDGFRA in $40 \%$ of adventitial Sca-1+ cells

31. Mahdavi Gorabi A, Banach $M$, Reiner $Z$, et al. The role of mesenchymal stem

- cells in atherosclerosis: prospects for therapy via the modulation of inflammatory milieu. J Clin Med 2019; 8:00.

This review elaborates on recent progress pointing toward possible effective treatment of atherosclerosis with MSCs but at the same time discusses risks and gaps in knowledge that should be addressed.

32. Lukomska B, Stanaszek L, Zuba-Surma E, et al. Challenges and controversies in human mesenchymal stem cell therapy. Stem Cells Int 2019; 2019:9628536

33. Musiał-Wysocka A, Kot M, Majka M. The pros and cons of mesenchymal stem cell-based therapies. Cell Transplant 2019; 28:801-812. 